\title{
¿Qué es, si es que es algo, una raza humana?
}

\author{
What, if anything, is a human race?
}

\author{
Gustavo Caponi \\ Universidade Federal de Santa Catarina (UFSC) \\ Orcid 0000-0002-3975-8367 \\ gustavoandrescaponi@gmail.com
}

Resumen: No hay ningún concepto de raza que, al aplicarse al Homo sapiens, encuentre su extensión en un grupo de linajes evolutivamente diferenciables. Consecuentemente, desde un punto de vista filogenético, las razas humanas son una ficción. Sin embargo, las 'razas humanas' pueden llegar a funcionar como predicados con algún grado de relevancia epistémica. Esos 'predicados raciales' especificarían ciertos tipos fisonómicos, de extensión relativamente delimitable, $\mathrm{y}$ con algún contenido disposicional, que pueden ser significativos en distintos contextos de discusión. Muy particularmente, cuando se trata identificar a grupos, e individuos, que puedan encontrarse en condiciones de vulnerabilidad, o que puedan venir a ser beneficiarios de políticas de acción afirmativa.

Palabras clave: Acción Afirmativa; Clase Natural; Linaje; Razas; Tipos Fisonómicos.

Abstract: There is no concept of race that, when applied to Homo sapiens, can find its extension in a group of evolutionarily differentiable lineages. Consequently, from a phylogenetic point of view, human races are fictions. However, 'human races' may function as predica- 
tes with some degree of epistemic relevance. These 'racial predicates' would specify certain physiognomic types, of relatively well-delimited extension, and with some dispositional content, which may be significant in different discussion contexts. Particularly when it is matter of identifying groups, and individuals, that may be in conditions of vulnerability, or that may become beneficiaries of affirmative action policies.

Keywords: Affirmative Action; Lineage; Natural Kind; Physiognomic Type; Race.

El título de este trabajo es la paráfrasis de una paráfrasis. A fines de los años cincuenta, Albert Wood (1957) publicó un artículo en Evolution cuyo título fue "What, if anything, is a rabbit?". Ahí se indagaba la posible vinculación filogenética del orden Lagomorpha (compuesto por conejos, liebres y picas) con el orden Rodentia (compuesto por ratones, ratas, ardillas, castores, capibaras, etc.); y se concluía que Lagomorpha es un grupo natural, un genuino grupo monofilético, que no guarda mayor proximidad evolutiva con Rodentia. Los conejos, por lo tanto, no son roedores. Lo cierto, sin embargo, es que yo sólo supe de ese trabajo por la referencia que a él hizo Stephen Jay Gould (1984) en "¿Qué es, si es que es algo, una cebra?": un texto, este otro, en el que se discute si las tres especies de cebras (Equus burchelli, Equus zebra y Equus grevyi) constituyen o no un grupo natural: un grupo filogenéticamente real. En ese sentido, mi paráfrasis no es infiel, ni a la formulación original, ni tampoco a la de Gould; que fue mi verdadera referencia.

Digo esto porque la noción de grupo natural, en el sentido filogenético del término, también está involucrada en la pregunta que estoy formulando. Si las supuestas razas de Homo sapiens son entidades realmente existentes, si ellas son grupos naturales; entonces, debería ser posible tratarlas como sub-linajes de nuestra especie, que es lo que habitualmente hacen aquellos que sostienen esa existencia. Sin embargo, pese a su aparente simplicidad, ese de modo de proceder, según inten- 
taré mostrarlo, no es factible. No lo es porque no hay ningún concepto de raza que, al aplicarse al Homo sapiens, encuentre su extensión en un grupo de linajes evolutivamente diferenciables. A no ser, claro, que por 'raza' se entienda algo cuya extensión resulte totalmente distinta de lo que habitualmente se piensa cuando se usa dicha expresión. Por otra parte, y conforme también espero mostrarlo, en todas las tentativas de tratar a las razas humanas como linajes siempre se cuela una tipología racial tácita; como si el registro filogenético se superpusiese y se mezclase, inevitablemente, con un registro tipológico.

Pero, aunque esa superposición del registro filogenético con el registro tipológico deba ser evitada, eso no quiere decir que toda y cualquier conceptualización tipológica de las razas sea siempre, bajo todo punto de vista, impugnable. Porque, aunque no pueda considerárselas como entidades biológicas efectivamente existentes, aunque no pueda considerárselas como linajes pasibles de entrar en el registro filogenético, en determinados contextos, las 'razas humanas' pueden llegar a funcionar como tipos con alguna relevancia epistémica. Los 'predicados raciales', como ‘ser negro' o 'ser blanco', especifican ciertos tipos fisonómicos, de extensión relativamente delimitable, y con algún contenido disposicional, que pueden ser significativos en distintos contextos de discusión. Muy particularmente, cuando se trata identificar a grupos, e individuos, que puedan encontrarse en condiciones de vulnerabilidad, o que puedan ser beneficiarios de políticas afirmativas.

Hablaré de tipos fisonómicos, y no de fenotipos, por una cuestión de precisión. El punto de partida de las tipologías raciales no está en los fenotipos considerados en su totalidad. Las categorías raciales sólo se basan en aspectos y detalles morfológicos superficiales identificables a simple vista; aunque eventualmente registrables en base a algún aparato y sistema de medición. El largo del intestino, que es un rasgo fenotípico, no es considerado por ninguna tipología racial; como sí ocurre, en cambio, con el color de la piel, la forma y el color de cabello, la estatura, la forma de la cabeza, la forma y el color de los ojos, de los arcos superciliares, de la nariz, de los labios, etc. Así, aunque uso la expresión 'fisonomía' en su sentido amplio, como 
aludiendo a todos los rasgos exteriores de una persona y no sólo a sus rasgos faciales, es innegable que en las tipologías raciales la fisonomía facial es preponderante por sobre cualquier otro rasgo corporal. Siendo sobre todo a partir de esos rasgos que se establecen esos tipos fisonómicos cuyos límites son más o menos nítidos, aunque nunca plenamente desprovistos de algún grado de arbitrariedad.

Es que, aunque los rasgos a los que esos tipos raciales aluden sean realidades biológicas no menos efectivas que otros aspectos del fenotipo, la elección y la estipulación de los atributos que vayan a ser considerados como propios y delimitadores de una raza, siempre va a depender, en mayor o menor medida, de los contextos culturales en los que las taxonomías raciales se configuran; y también de los objetivos, teóricos o prácticos, a los que responden tales taxonomías. El color de los ojos, para dar un ejemplo muy claro, es una realidad biológica tan efectiva como cualquier otro aspecto del fenotipo. Pero que dicho color sea o no considerado como un rasgo racial, puede no llegar a tener un fundamento biológico sólido; y esa consideración puede depender de lo que se quiera hacer, desde un punto de vista teórico o práctico, con la tipología racial que esté siendo propuesta o adoptada.

Este modo de entender las razas, lo sé, puede tener derivas racistas. No menos que las que pueda tener pensarlas como linajes. La obra The bell curve de Richard Herrstein y Charles Murray (1994, p.317) es un claro ejemplo de eso (Lewontin et al, 2003, p.31-2; Sussman, 2014, p.304-5). Allí, los grupos raciales son distinguidos en virtud de criterios puramente fisonómicos, y el coeficiente de inteligencia, aparece correlacionado con esos tipos; sin que se pretenda hacer entrar en consideración ni la Genética y ni la ascendencia. Por eso, el uso de esos tipos exige la adopción de algunas precauciones metodológicas que ya señalé y defendí en un texto anterior ( $c f$. Caponi, 2018a). Ante ese tipo de racismo debe adoptarse, en efecto, la línea de argumentación desplegada en obras paradigmáticas como La falsa de medida del hombre, de Stephen Jay Gould (1988) y No está en los genes: racismo, genética e ideología, de Richard Lewontin, Steve Rose y Leon Kamin (2003). 
Dicha estrategia argumentativa anti-racista es más ardua pero también más eficiente que la simple negación de esos tipos fisonómicos, de los que puede valerse el racismo, pero que también son presupuesto de las políticas afirmativas.

Pero aquí, en lugar de analizar esas estrategias argumentativas anti-racistas, me limitaré a dejar por sentado que, con los términos 'racismo' y 'racista', aludiré a toda y cualquier posición que asocie las particularidades fisonómicas que se puedan atribuir a ciertos grupos humanos, y a los individuos a ellos pertenecientes, bien como la filiación de esos grupos e individuos, con diferencias relativas a capacidades cognitivas y disposiciones emotivas. Eso con independencia de cuáles sean los argumentos ofrecidos para establecer dicha vinculación y de cuáles sean las consecuencias morales y políticas que de ahí pretendan derivarse. Es decir: consideraré racista a todo aquel que suponga o proponga esa vinculación. Sólo se trata de una definición, no de un epíteto; y de la misma de deriva que el calificativo 'racista' puede ser usado con relativa independencia de la autopercepción del sujeto al cual se lo aplica y con relativa independencia del contexto histórico en el cual esa posición sea adoptada.

\section{Una palabra a la búsqueda de un concepto}

Los biólogos no parecen poder ponerse de acuerdo sobre cuál es la mejor definición del concepto de especie (cf. Coyne \& Orr, 2004, p.447): las discusiones al respecto parecen inacabables ( $c f$. Richards, 2010; Torretti, 2010). Pese a eso, en la mayor parte de los casos, la aplicación de dicho concepto no resulta problemática. Como ocurre con 'Panthera leo' y con 'Homo sapiens', la amplísima mayoría de las designaciones de especies pueden usarse como ejemplos no problemáticos de lo que entendemos por 'especie'; como también existen innúmeros casos relevantes en los que la impredicabilidad de ese concepto se muestra obvia e indiscutible. Sabemos que 'Panthera' designa un agrupamiento de linajes que no puede caracterizarse como una especie; y lo mismo vale para 'Panthera leo persica'. Siendo esos casos no problemáticos de predicabilidad, y de impredi- 
cabilidad, que sirven de referencia para las arduas discusiones sobre los contornos del concepto de especie. A partir de esos casos, caracterizables como paradigmáticos, es dable intentar el trayecto que es típico de toda elucidación conceptual: del caso indiscutido a la regla de uso; y desde ahí a los casos problemáticos. Sin olvidar, por supuesto, que el tratamiento del caso problemático siempre podrá obligarnos a revisar la enunciación de la regla.

En cambio, con la noción de raza humana la situación es otra, y mucho más complicada de la que se da con la noción de especie. Esta última es, en primer lugar, una categoría taxonómica de cuya pertinencia nadie duda, cosa que no ocurre con la noción de raza humana. Pero, además de eso, cuando consideramos la idea de raza humana, también nos encontramos con el problema de que no existen ejemplos no problemáticos de esa noción. No sólo no existe una lista definida y aceptadas de razas humanas, que por lo menos todos los usuarios de esa noción acepten ( $c f$. Mayr, 1963, p.644); sino que tampoco existe un ejemplo, un ítem posible de esa lista, que pueda ser considerado como incuestionablemente paradigmático de lo que se quiere decir cuando se habla de una 'raza humana'. Eso imposibilita ese tránsito desde el caso paradigmático a la regla que es característico del análisis filosófico.

Considérese, sin ir más lejos, el ejemplo de esa soi disant 'raza blanca', o 'caucásica', que aparece en todas las clasificaciones de variedades humanas que se construyeron desde el Siglo XVIII en adelante. Sea en esas clasificaciones que pretendían aludir a diferentes especies de hombre, o en aquella que pretendían referirse a diferentes variedades dentro de una misma especie, el hombre blanco siempre aparece como uno de sus ítems. En su lista de cuatro especies de hombres, Voltaire (1948[1734], p.138) incluía a los 'blancos barbados' de Europa. Linneo (1788, p.22) distinguía seis variedades de Homo sapiens; y una de ellas era el Homo sapiens europaeus. Blumenbach (1865[1795], p.264), en cambio, llegó distinguir cinco variedades de hombre, pero una de ellas era la 'caucasiana'; que se correspondía con el hombre blanco de Voltaire, con el europeo de Linneo, y también con el blanco de la lista 
cuádruple que Kant (1964[1785], p.70) propuso en "Definición de la raza humana". Cuvier (1817, p.99), por su parte, aun reduciendo su lista de razas a tres, conserva a la 'blanca o caucásica' como una de ellas; que es lo mismo que hace Gobineau (1853, p.245).

Pero, aun en listas de razas o especies humanas mucho más frondosas, el hombre blanco de Voltaire sigue apareciendo. Es uno de los dieciséis tipos de hombre distinguidos por Louis Agassiz (1854, p.lxxviii); y es una de las doce especies del género Homo que, ya en un contexto evolucionista, Haeckel (1947[1868], p.544) enumera en su Historia Natural de la Creación de los Seres organizados. El mismo hombre blanco que, también en un contexto evolucionista, Ameghino (1907, p.222) llama especie 'caucásica'; oponiéndola a la mongólica, a la amerindia, y a la negra. Ameghino, podríamos decir, vuelve a las cuatro razas de Kant; pero, a la manera de Voltaire, él las considera como especies diferentes. Siendo esa misma lista cuádruple que se preserva en la Antropología Forense norteamericana. Allí se ofrecen cuatro rótulos raciales para caracterizar restos humanos o para describir personas perdidas: negro, blanco, mongoloide, y americano nativo (Sauer, 1992, p.110); y esa lista se preserva, con algún que otro agregado o substracción, en diferentes sistemas de información de distintos países (cf. Spencer, 2014, p.1036; Santos et al, 2017, p.5).

Sin embargo, pese a la constancia que el ítem 'blanco' o 'caucásico' tiene en todos esos listados que vengo mencionando, lo cierto es que, en la biología actual, esa categoría, al igual que las otras tres o cuatro con los que ella suele venir acompañada (mongoloide; negro; americano; y, a veces, malayo), muy difícilmente podría ser aceptada como un taxón sub-específico de Homo sapiens. Quizá, la estabilidad de esa rúbrica taxonómica puede hacer pensar que ella alude a algo real; pero, en este caso por lo menos, esa expectativa podría verse contrariada. En el contexto de la Biología Evolutiva actual, y particularmente en el contexto de la Sistemática Filogenética, no hay cómo atribuirle realidad a ese pretendido taxón: el mismo no es pasible de ser considerado un grupo natural. El problema, entretanto, es que la propia explicación de por qué eso es así, tampoco deja 
de ser problemática. Pueden darse dos o tres argumentos diferentes para mostrar que las razas señaladas por Blumenbach o por Cuvier no pueden ser consideradas grupos reales; pero cada una de esos argumentos supone una conceptualización diferente de lo que hemos de entender por razas humanas.

Se podría pensar que, para elucidar la noción de raza humana, debería comenzarse por algún concepto general de raza: ése que los biólogos aplicarían en el caso de cualquier especie politípica que así lo exigiese. Al fin y al cabo, se podría argumentar, Homo sapiens es una especie biológica como cualquier otra; y las categorías taxonómicas sub-específicas que sean aplicable a ella, no pueden ser diferentes de las que se aplican en las demás especies. El problema, entretanto, es que las categorías taxonómicas sub-específicas distan de estar claras; y el vocabulario que se usa para aludir a dichas categorías siquiera esta unificado. 'Raza', por ejemplo, es un término del cual no pocos taxónomos prescinden ( $c f$. Eldredge \& Cracraft, 1980; Wiley \& Lieberman, 2011); y, cuando se lo ha usado, se lo hizo según dos acepciones diferentes. Una sería la que suele referirse con la expresión 'raza geográfica'; y la otra es la que suele referirse con la expresión 'raza ecológica'. Aunque, como veremos, también se pueda cuestionar la posibilidad de distinguir ambas nociones (cf. Mayr, 1942, p.193).

Cómo sea, el Cambridge Dictionary of Human Biology and Evolution nos da dos buenas definiciones de ambos conceptos. Según sus autores, una raza geográfica sería "una población que está geográficamente separada de otras poblaciones de la misma especie, con las cuales podría entrecruzarse, y que ha evolucionado al punto de poder ser considerada una subespecie o especie incipiente" (Mai et al, 2005, p.216); y eso ratifica lo que Ernst Mayr (1942, p.193) ya había dicho al respecto en Systematics and the origin of species. Mientras tanto, según ese mismo diccionario, una raza ecológica sería "una variante local de una especie que presenta caracteres adaptativos seleccionados para un ambiente o hábitat local" (Mai et al, 2005, p.1601); y eso, como también Mayr (1963, p.355) ya lo había observado, aproxima la noción de raza con la de ecotipo (Mai et al, 2005, p.161). Un ecotipo sería "una población de una especie 
de amplia distribución que está adaptada y restringida a una localidad particular (Mai et al, 2005, p.161) ${ }^{1}$. Cabiendo decir, entonces, que mientras la noción de raza geográfica se asimila a la subespecie, la de raza ecológica se homologa a la de ecotipo (cf. Mayr, 1963, p.350-1; Lincoln et al, 2009, p.507-8).

Eso, sin embargo, no es algo que está libre de cuestionamiento. Se podría argumentar, como Mayr (1963, p.357) lo hizo, que no es dable distinguir entre raza geográfica (o subespecie) y raza ecológica (o ecotipo), porque toda raza geográfica presenta características propias que obedecen, en gran medida, a las exigencias del entorno en el que ella se distribuye. En este sentido: "todas las razas son tan geográficas como ecológicas" (Mayr, 1963, p.358). Pero, aunque aceptar esa posición de Mayr simplificaría mucho nuestra discusión - sólo precisaríamos preguntarnos si en Homo sapiens pueden distinguirse subespecies -, lo cierto es que, si hiciésemos eso, estaríamos planteando el problema de las razas humanas en un nivel taxonómico que no todos considerarían pertinente. Cuando Massimo Pigliussi y Jonathan Kaplan (2003) proponen pensar a las razas en general, y a las razas humanas en particular, como ecotipos, ellos no parecen dispuestos aceptar la homologación entre ecotipo y subespecie. Los ecotipos, según ellos los entienden, no necesariamente serían unidades filogenéticas distinguibles como las subespecies y pasibles, como ellas, de ser tratados como unidades taxonómicas diferenciadas. Por eso preferiré desdoblar el planteo de la cuestión: primero mostraré las razones por las cuales no cabe distinguir subespecies de Homo sapiens; y luego mostraré que, el fundamento último de esos mismos argumentos, también nos sirve para desestimar la propuesta de Pigliussi y Kaplan.

\footnotetext{
1 Se trata, ciertamente, de una definición estándar de ecotipo (cf. Lincoln et al, 2009, p. 191; Futuyma, 2005, p.547); y que, además, se corresponde con el sentido que, originalmente, el botánico sueco Göte Turesson (1922a, p.112; 1922b, p.345) le dio al término (cf. Mayr, 1963, p.355).
} 


\section{De la especie a la subespecie}

Las aparentemente inacabables polémicas sobre la definición del concepto de especie, a las que aludí en el inicio de la sección anterior, pueden parecer un obstáculo insuperable para cualquier tentativa de definir la noción de subespecie. Se podría muy bien pensar que, si no hay acuerdo sobre qué es una especie, mal puede existir acuerdo respecto de qué es una subespecie. Con todo, en las diferentes tentativas de elucidar el concepto de especie que se han dado en la Biología contemporánea, es dable identificar un denominador común que puede darnos una primera y buena clave para una delimitación mínimamente satisfactoria de la noción de subespecie; por lo menos en lo que respecta a posibles subespecies que puedan darse en especies de homínidos, o de cualquier otro grupo de mamíferos. Aludo, al hecho, reconocido e incuestionado de que, en la Biología contemporánea, las especies deben ser pensadas en términos poblacionales ( $c f$. Simpson, 1951, p.287): ellas deben ser consideradas como poblaciones, o linajes de poblaciones, que guardan ciertas relaciones biológicas entre ellas. Y eso es así aunque no sea tan fácil delimitar y caracterizar, en general y de modo preciso, la naturaleza de tales relaciones.

Podemos decir que, en la Biología actual, las especies son agrupamientos, o linajes, de poblaciones cuyos procesos evolutivos están interconectados; pero son relativamente independientes de los procesos evolutivos que se dan en otros linajes o agrupamientos semejantes. Eso es lo que George Gaylord Simpson intentaba consignar en ese Concepto Evolutivo de Especie que hoy también es reivindicado por autores como Wiley (1981, p.25); Mayden (2002, p.184); Richards (2007, p.219); y De Keiroz (2011, p.27). Según el mismo, una especie es "un linaje filético (una secuencia ancestro-descendiente de populaciones entrecruzables) que evoluciona independientemente de los otros linajes, y tiene un papel evolutivo separado y unitario, con sus propias tendencias" (Simpson, 1951, p.289); siendo justamente en la amplitud, o en la vaguedad, de las ideas de independencia y de separación evolutivas en donde reside tanto la mayor virtud, como la mayor dificultad, de esa definición de especie. Ella 
nos propone un concepto muy general, aplicable a toda suerte de taxón, pero cuyos contornos no son demasiado claros.

De todos modos, dadas ciertas peculiaridades de la especie que nos ocupa, y que ella comparte por lo menos con todos los mamíferos, es posible y pertinente acotar esas ideas de independencia y separación evolutiva recurriendo a la noción de aislamiento reproductivo; y con eso llegamos al Concepto Biológico de Especie, que alude a un tipo particular de aislamiento evolutivo entre linajes, o grupo de poblaciones. Un tipo de aislamiento evolutivo, que se da en linajes de seres vivos de reproducción sexuada, y que consiste en mecanismos que, al obstaculizar la hibridación, dificultan el flujo genético desde y hacia afuera de un determinado grupo o linaje de poblaciones. Puede decirse, por eso, que dicha especificación del Concepto Evolutivo de Especie es perfectamente aplicable e indudablemente pertinente al taxón que nos ocupa; permitiendo que, en lo que atañe a esa aplicación en particular, el concepto evolutivo cobre contornos más definidos. Así, aunque el Concepto Biológico de Especie haya sido objetado porque sólo es significativo cuando se consideran linajes de organismos en donde existe la reproducción sexuada ( $c f$. Caponi, 2013, p.398); al tomarlo como siendo únicamente una posible especificación de un concepto más general, podemos aceptar su aplicación en el caso que está aquí en discusión.

Según la formulación del Concepto Biológico de Especie propuesta por Mayr (2007[1963] p.205; 2000, p.17): "las especies son grupos de poblaciones naturales entrecruzables que están reproductivamente aisladas de otros grupos semejantes"; y ese aislamiento reproductivo entre poblaciones puede resultar de una multiplicidad de mecanismos, pasibles de clasificarse en tres grandes tipos: barreras que impiden o dificultan el apareamiento (v.g. incompatibilidades en comportamientos y temporadas de apareamiento); barreras que precigóticas que obstaculizan la fertilización (actuando, por ejemplo sobre polen y esperma) ; y barreras postcigóticas que inviabilizan o esterilizan a la progenie resultante del cruzamiento (Coyne \& Orr, 2004, p.28-9). Así, aunque existan poblaciones de Canis lupus y de Canis latrans coexistiendo en una misma área geográfica, 
y aunque no existan barreras pre o postcigóticas que impidan que del eventual apareamiento de un coyote y una loba surja un hibrido fértil, eso no obsta para considerar que esos dos linajes de Canis constituyen especies diferentes. La existencia de ciertas incompatibilidades en los comportamientos de apareamientos de ambos linajes, hace que los cruzamientos sean poco frecuentes; y eso ratifica que estamos ante dos especies diferentes. Aunque se trate, ciertamente, de especies cuya separación evolutiva sea incipiente, y todavía relativamente porosa.

En realidad, lo que aquí más importa es la asociación que puede establecerse, por lo menos en ciertos casos, entre separación evolutiva y flujo genético. Podemos decir que, la separación e independencia evolutiva de especies como Canis lupus, Canis latrans, y también Homo sapiens, está asociada a esas limitaciones del flujo genético que, en mayor o menor grado, aíslan a esos linajes de otros linajes semejantes. Pensemos, otra vez, en las barreras comportamentales que puedan separar a esos dos linajes del género Canis; y pensemos también en los posibles mecanismos que pudieron levantar esa permeable barrera reproductiva que pudo haber separado a Homo sapiens de Homo neanderthalensis. Podemos hablar de especies diferentes, de linajes diferentes; porque ese aislamiento reproductivo, más o menos poroso, genera cierto aislamiento microevolutivo: los procesos microevolutivos que se dan en los diferentes sub-linajes de esas especies, tienen poco o nulo impacto en sub-linajes de otras especies; y, a su vez, son escasa o nulamente afectados por los procesos microevolutivos ocurridos en esos sub-linajes de otras especies ${ }^{2}$.

La especie aparece así como un espacio definido por los límites y la intensidad del flujo genético. Entre los linajes de una misma especie, ese flujo se da, o puede darse, con una fluidez e intensidad que es mucho mayor que la que puede darse desde y hacia linajes de otras especies. En este último caso, es verdad, ese flujo es, por lo general, nulo; pero aquí yo prefiero

$2 \quad$ Por definición, los procesos microevolutivos son aquellos que ocurren al interior de una población o de una especie. Son los procesos enumerados en el Principio de Hardy-Weinberg: selección natural, selección sexual, deriva génica, y mutación. Al respecto, ver: Caponi (2013). 
que no olvidemos los casos en donde el mismo, aunque poco intenso, escaso y muy ocasional, no deja de persistir. Quiero que tengamos eso en cuenta; porque, a partir de ahí, podemos concebir una delimitación del concepto de subespecie que nos resulte operativa para discutir si, en el caso de Homo sapiens, es dable distinguir subespecies. Es que, si la especie se define en virtud de esas restricciones al flujo genético que hacen que éste sea más fluido e intenso entre ciertos linajes, y nulo, o muy escaso, entre esos linajes y otros; entonces, la subespecie puede pensarse en virtud de alguna discontinuidad, o irregularidad, en el flujo genético que se da entre los linajes de una misma especie. Las subespecies, cabe así decir, son linajes de poblaciones de una misma especie entre los que se da un flujo genético mayor que el que se da entre esos linajes y otros que consideramos como integrando otras subespecies de la misma especie.

Dicha irregularidad del flujo genético puede obedecer a distintos factores. Pero el más obvio es la separación geográfica. Por eso, el mismo suele aparecer en el propio definiens de la noción de subespecie; permitiendo, además, la ya apuntada homologación entre dicha noción y la de raza geográfica. Así, según la definición propuesta por Ernst Mayr (1963, p.348): "Una subespecie es un agregado de poblaciones locales de una especie, que habita una subdivisión del área de distribución de la especie, y que se diferencia taxonómicamente de otras poblaciones de la especie"; y eso no difiere de la definición que más tarde daría Stephen Jay Gould (1995, p.164). Según la misma: "las subespecies son poblaciones que ocupan una subdivisión geográfica concreta de la distribución de una especie y que son suficientemente diferentes en cualquier serie de rasgos como para ser taxonómicamente reconocibles". Y, conforme lo estipulado por la International Commission of Zoological Nomenclature (1999, p.131) esa individualización taxonómica, a la que Mayr y Gould aluden en sus definiciones, se expresa por designaciones trinomiales. En ellas, las designaciones binomiales de las especies, como Panthera leo, se complementan con una última determinación (ver también: Simpson, 1945, p.14; Mayr, 1963, p.348). Así, el león asiático se designa con 
la expresión Panthera leo pérsica; y el africano con la expresión Panthera leo leo.

Pero, lo que aquí más debe importarnos es que, según esas definiciones, "las subespecies habitan un área específica" (Mayr, 1963, p.349); y eso indica una cierta discontinuidad en el área de la distribución de la especie. Las subespecies, se está suponiendo, presentan algún aislamiento geográfico entre ellas, que puede ser más o menos pronunciado; pero que tiende a ser menos pronunciado que el que se da entre las poblaciones que las integran. En general, las poblaciones de una subespecie están menos geográficamente aisladas entre sí que lo que lo están de las poblaciones de otras subespecies; y eso incide en el flujo genético que puede ocurrir entre las diferentes poblaciones de una misma subespecie. Éste es mucho más intenso $\mathrm{y}$ frecuente que el que puede darse entre las poblaciones de subespecies diferentes. Por eso, para distinguir las posibles subespecies, o razas geográficas, de una especie cualquiera de mamíferos, lo que tenemos que hacer es identificar linajes de poblaciones que, al distribuirse en áreas diferentes, también se segregan, o aíslan, en términos de flujo genético ( $c f$. Futuyma, 2005, p.551; Templeton, 2018, p.448). Eso ocurre claramente en el caso de Panthera leo leo y Panthera leo asiática; y, en principio, podría valer para diferentes linajes de Homo sapiens.

\section{Las razas como subespecies}

El problema, sin embargo, reside en saber cuáles serían esos linajes. Los mismos, ciertamente, no podrían tener nada que ver con aquellas razas humanas a las que aludían Linneo, Blumenbach, o Cuvier; y a las que todavía aluden los antropólogos forenses (cf. Adams, 2007, p.43). Así, si consideramos el tipo fisonómico que dichos naturalistas, y esos antropólogos, llamarían blanco o europeo, podríamos ver que individuos que responden a él, así como familias y grupos de tales individuos, se encuentran distribuidos por muy diferentes regiones en donde también encontramos individuos, familias y grupos que responden a otros tipos fisonómicos como podrían ser el tipo negro o el tipo amerindio. Y no sólo eso: en general esa coincidencia en una 
misma área geográfica hace que esos individuos, que responden a diferentes tipos fisonómicos, estén integrados en una misma comunidad reproductiva. Que es lo mismo que decir que están integrados en una misma población; $y$, si se acepta que las poblaciones son el componente básico de los taxones, resulta difícil pensar que individuos claramente integrados en una misma comunidad reproductiva, puedan recibir adscripciones taxonómicas diferentes. A no ser, por supuesto, que se quiera reintroducir un toquecito de tipología en la Taxonomía.

Por otra parte, aunque los rasgos fisonómicos, y otros elementos fenotípicos y genotípicos, puedan servir para rastrear la ascendencia de esos grupos e individuos, denunciando que los mismos descienden de individuos o grupos oriundos de determinadas regiones de la Tierra, o que incluso ellos, los propios individuos, son oriundos de ahí (cf. Rosenberg et al, 2002, p.2382; Wade, 2015, p.79; Templeton 2018, p.455), eso no nos releva de considerarlos como parte de la comunidad reproductiva, o población, dentro de la cual efectivamente se encuentra y en la cual habrán de aparearse, dejando progenie. Y observo, por las dudas, que, cuando un individuo migra de una población a otra; lo que ocurre, claro, es que él deja de ser parte de una población y pasa a ser parte de otra; más allá de su filiación y de sus características particulares.

El hecho de que los descendientes de japoneses que habitan en Brasil sean, efectivamente, descendientes de japoneses, nada informa sobre la comunidad reproductiva, o población, a la cual están integrados. Y nada cambia si la genealogía evidenciada, u ocultada, por la fisonomía de los individuos considerados, es ratificada o puesta en evidencia por algún elemento genotípico. Por eso, si los taxones son pensados en términos poblaciones, esos descendientes de japoneses no podrán considerarse como partes de la misma raza geográfica, o subespecie, de los japoneses que habitan en los Estados Unidos. Además, aunque puedan existir barreras culturales que obstaculizan y hacen menos frecuentes los apareamientos entre individuos que responden a diferentes tipos fisonómicos - tal como suele ocurrir entre negros y blancos -, lo cierto es que entre los blancos y negros brasileños tiende a existir más flujo genético 
que el que existe entre blancos brasileños y blancos suecos, o entre afrobrasileños y afrocanadienses.

Las poblaciones humanas actuales, ya lo sabemos, presentan, en su mayoría, una gran heterogeneidad en lo que respecta a la genealógica de sus miembros. Eso se refleja en una alta variabilidad genética intrapoblacional que, asociada a una baja variabilidad genética interpoblacional ${ }^{3}$, ha sido justamente considerada como una de los argumentos más fuertes para negar la posibilidad de distinguir razas de Homo sapiens (MacEachern, 2011, p.42-3). Sobre todo, si queremos pensar que esas razas serían análogas a las subespecies que suelen distinguirse en el caso de otras especies (MacEachern, 2011, p.43; Templeton, 2018, p.464). Como Alan Templeton (1998, p.635; 2018, p.456) lo mostró, la variabilidad genética entre las poblaciones humanas se coloca muy por debajo de la que los biólogos consideran como necesaria para distinguir subespecies en otras especies. Aunque tomemos dos poblaciones geográficamente tan aisladas, como podría ser el caso de los Korubos del Amazonas y los Pintupi de Australia Occidental, la variabilidad genética entre ellas será menor que la que encontremos entre dos subespecies reconocidas de cualquier otra especie. Pensemos, otra vez, en Panthera leo persica y Panthera leo leo. Y hay una explicación biológica para eso.

Homo sapiens es una especie reciente; y su radiación geográfica también lo es. Aunque, en razón de las habilidades cognitivas de nuestra especie, y sobre todo en virtud de la plasticidad de esas habilidades, el área de distribución que ella acabó ocupando, en relativamente poco tiempo, fue vastísima. Es decir: la notoria radiación geográfica de Homo sapiens no sólo es reciente (Gould, 1995, p.165), sino que además fue muy rápida. Eso puede explicar que dicha radiación no haya resultado en tanta diferenciación genética inter-poblacional. Pero, los mismos factores que explican esa rápida radiación también pueden hacernos pensar en la posibilidad de constantes y múltiples retro-cruzamientos entre los linajes divergentes. Al

3 Al respecto, ver: Biondi \& Rickards (2002, p.377); Rosenberg et al (2002, p.2381); Kattmann (2013, p.134); Hochman (2013, p.283); y Templeton (2013, p.267; 2016, p.464). 
tiempo en que estos se separaban ocupando diferentes regiones de la Tierra, el flujo genético entre ellos tampoco cesaba (Templeton, 1998, p.647; Kattmann, 2013, p.136). El aislamiento geográfico es función, entre otras cosas, de las capacidades de migrar, o de desparramar sus semillas o su polen, que presenta cada grupo de seres vivos; y siendo el Homo sapiens una especie de gran capacidad migratoria, podemos pensar que lo mismos factores que posibilitaron su radiación también posibilitaron el permanente retro-cruzamiento y las anastomosis entre los linajes previamente divergentes ( $c f$. Mayr, 1963, p.644; Gould, 1995, p.164). Lo que parece confirmado por estudios moleculares sobre la historia genética de los diferentes grupos humanos (Templeton: 2013, p.264; 2018, p.459).

Es decir: esos estudios que Templeton (1998, p.446; 2018, p.460) señala, no sólo muestran que no hay subespecies discernibles en el Homo sapiens actual; sino que también permiten inferir que tampoco llegó a haberlas en el pasado de la especie (cf. Sussman, 2014, p.8): el flujo genético entre las diferentes poblaciones de Homo sapiens fue siempre lo suficientemente intenso y constante como para que pudiesen perfilarse linajes cuyo aislamiento evolutivo permitiese tratarlos como subespecies". Lo que, además, no tiene nada de raro. "La subespecie", como hace mucho lo puntualizó George Gaylord Simpson (1961, p.173), "es una categoría no obligatoria y no es necesario, ni siquiera en principio, que ella sea usada a lo ancho de toda la clasificación". Es decir: no es extraño que haya especies en donde no sea posible discernir subespecies. Eso no sería una singularidad de nuestra especie; y, como acabamos de ver, no faltan factores biológicos para explicar esa 'contingencia' evolutiva ( $c f$. Gould, 1995, p.168).

Así, en virtud de las mismas consideraciones de Templeton, también se puede impugnar el recurso que Robin Andreasen (2006, p.487) hizo a lo que podría caracterizarse como un 'concepto cladístico de raza' ( $c f$. Andreasen, 2005, p.95; Kitcher, 2007, p.296). Según Andreasen (2006, p.491), en el estado actual de cosas, las razas humanas ya no existen: el copioso

$4 \quad$ Así lo han afirmado: Cartmill (1998, p.659); MacEachern (2011, p.44); Kattmann (2013, p.137); y Templeton (2018, p.461). 
flujo genético que se ha dado entre las diferentes poblaciones humanas habría apagado las diferencias raciales (Andreasen, 2006, p.491). Pero, en su opinión, ellas existieron en el pasado; cuando Homo sapiens comenzó a divergir en linajes que se separaron y aislaron entre sí al dispersarse por diferentes regiones (Andreasen, 2006, p.488). Esos linajes divergentes conformaron grupos monofiléticos que evolucionaron en relativo aislamiento dando lugar a subespecies que hoy habrían vuelto a fundirse; y es a esas subespecies que Andreasen (2006, p.491) denomina razas. Con todo, si aceptan los datos esgrimidos por Templeton (1998, p.640; 2013, p.269; 2018, p.457), tenemos que concluir que esos linajes divergentes nunca se aislaron de una forma tan marcada y constante que fuese compatible con la distinción entre subespecies (cf. Pigliucci \& Kaplan, 2003, p.1164; Templeton, 2018, p.461).

Pero, aunque los argumentos de Templeton parecen alcanzar las tesis de Andreasen, es posible que no alcancen a las de Philip Kitcher. Para éste, una raza sería un linaje que, a causa de cierto aislamiento geográfico, se aparta reproductivamente de otros linajes de su misma especie, y eso da origen a ciertas diferencias fenotípicas y a algunas interferencias al entrecruzamiento con otros linajes que se mantiene cuando el aislamiento geográfico se rompe (Kitcher, 2007, p.296). Pero, en contra de lo que Kitcher pretende, ese concepto no se aplicaría al caso de Homo sapiens. Quizá sí a otras especies; pero no a la nuestra. Entre todos los sub-linajes de Homo sapiens que podamos querer distinguir no existe nada que pueda ser considerado como un límite al entrecruzamiento. Donde sea y como sea que dos poblaciones de tales linajes se encuentren, los apareamientos habrán de ocurrir, y no de forma excepcional, u ocasional. El mestizaje resultante, además, no tendrá límites ni topes postcigóticos. La llegada a América de europeos, a partir de fines del Siglo XV, y después de africanos, fue el mayor experimento a gran escala que mostró eso; aun cuando los linajes amerindios hayan pasado por un largo periodo de aislamiento geográfico.

Además, antes de eso, no ha existido migración, conquista o intercambio comercial que no acabase en profuso flujo genético, por no decir otra cosa; $y$, a partir de la segunda mitad del 
Siglo XIX, esas migraciones, conquistas e intercambios comerciales se transformaron en constantes y globales, sin que tampoco surja la más mínima sospecha de la existencia de algún mecanismo de aislamiento reproductivo. Kitcher (2007, p.297-8) sugiere, es verdad, que, en el caso del hombre, las interferencias al entrecruzamiento entre razas son culturales; pero creo que él sobrevalua el efecto biológico, y psicológico, de la condena a los llamados 'matrimonios interraciales', que se ha dado y se da en ciertas sociedades. Eso es algo cultural, en efecto; pero lo cierto es que no se trata de un inhibidor del deseo que se haya mostrado demasiado efectivo. La vertiginosa y copiosa miscegenación que siempre ha ocurrido en los encuentros, y en la convivencia, entre linajes de Homo sapiens nos muestra que esa condena no tiene efectos biológicos demasiado pronunciados. Los análisis de Templeton nos dan prueba de eso.

Como sea, pese a los prejuicios y las interdicciones, los genes siempre se han intercambiado desenfrenadamente: por abajo o por encima de los prejuicios raciales; entre las sábanas o entre los yuyos; en uniones legalizadas o no; en relaciones conyugales o extraconyugales; estables u ocasionales; por mutuo consentimiento o por la violencia. Por eso, aunque la segregación fisonómica generada por el prejuicio, y por las políticas de apartheid, puede generar guetos intra-poblacionales reconocibles a simple vista; en lo que atañe a acerbo genético, y también a características fenotípicas sin expresión fisonómica, esa segregación tiene poco impacto. Mucho menos impacto, sobre todo, que el que puede tener el aislamiento geográfico; que es el principal moderador del flujo genético entre poblaciones de Homo sapiens, y que parece ser el único factor que permite establecer, y justificar, una lábil e inestable distinción entre tales poblaciones. Donde hay vecindad siempre hay mestizaje; aunque éste no sea tan fácilmente reconocible. Y la razón de que el mestizaje no siempre sea tan visible como su amplitud haría esperarlo, fue muy bien explicada en el artículo "Color and genomic ancestry in Brazilians" (Parra et al, 2003).

Conforme sus autores afirman: una combinación de "fuerzas sociales", como puede ser el caso de los prejuicios raciales, es capaz de producir una población con grupos diferen- 
ciados por rasgos fisonómicos como el color de piel, aunque muy semejantes en lo que atañe a su pool genético; y el apareamiento entre hombre blanco y mujer negra que fue tan frecuente en el Brasil esclavista, nos da un buen ejemplo de eso (Parra et al, 2003, p.181). De dichos apareamientos, que tampoco dejaron de ser relativamente frecuentes después de la abolición, resultaba una descendencia en la que se daban individuos con fisonomías que podían ser más o menos próximas de la de uno $\mathrm{u}$ otro de los progenitores. Y eso era importante en lo que atañe al destino que le cabía a esa progenie: "los niños con más rasgos físicos africanos serían considerados negros, mientras que aquellos con rasgos más europeos serían considerados blancos; aun cuando unos y otros tuviesen la misma proporción de alelos africanos". Así, "en la próxima generación, los individuos de piel clara tenderían a casarse con blancos, y, al revés, los individuos más oscuros tenderían a casarse con negros"; y, de ese modo, en el largo plazo, dicho patrón de apareamiento interracial, resultaría en dos grupos, uno blanco y el otro negro, "los cuales, pese a todo, tendrían una proporción similar de ascendencia africana"

\section{Las razas como ecotipos}

Es innegable, de todos modos, que no existen dos poblaciones, de la especie que sea, cuyo acerbo genético sea idéntico. Algunas de esas diferencias tendrán que ver con cosas como el efecto fundador, la deriva génica, la selección sexual, los flujos migratorios, el simple surgimiento de variantes neutras en términos de su manifestación fenotípica, o indistintas en términos de la eficiencia funcional de esa manifestación. Pero, más allá de eso, siempre es posible que una parte, más o menos significativa, de esas diferencias entre las proporciones de alelos que pueden darse en las poblaciones de una misma especie, o de una misma población, obedezcan a alguna presión selectiva (Templeton, 2018, p. 462-3). Y es aquí en donde la noción de ecotipo, o raza ecológica, puede tener una función. Todas las

$5 \quad$ En contra de lo que Nicholas Wade (2015, p.80) parece pensar, ese desacoplamiento entre genes y apariencia hace difícil que se puede ir desde el ADN hasta la fisonomía de una persona. 
poblaciones de una especie, según venimos diciendo, guardan diferencias entre sí en lo que respecta a la composición de su pool genético, y también en lo que atañe a los valores medios de los estados de caracteres que sus miembros exhiben. Pero el concepto de raza ecológica, o ecotipo, sólo se aplicara en la medida en que una parte de esas diferencias obedezca a presiones selectivas propias de las diferentes ambientes en los que una población evoluciona ( $c f$. Turesson: 1922a, p.112; 1922b, 346; Pigliucci \& Kaplan, 2003, p.1165; Pigliucci, 2013, p.275).

Así, aunque a primera vista pueda verse alguna semejanza entre el concepto de ecotipo y el concepto de raza como población mendeliana, que fue propuesto por Dobzhansky, lo cierto es que la diferencia entre ambos es importante. Para Dobzhansky (1951, p.138), las razas podían definirse "como poblaciones mendelianas de una especie que difieren en la frecuencia de una o más variantes genéticas" (cf. Lipko \& Di Pasquo, 2008, p.228; Kattmann, 2013, p.133); y él sabía que eso transformaba a las razas en agrupamientos artificiales. Que dos poblaciones pudiesen o no ser consideradas de razas diferentes dependía de cuales fuesen los alelos que escogiésemos como referencia y de cuán grande era la diferencia de frecuencias entre ellos que fuésemos a considerar como suficiente para establecer una diferencia racial ( $c f$. MacEachern, 2011, p.45). En el caso de los ecotipos, sin embargo, esa arbitrariedad no cabe. Los mismos deben diferenciarse en virtud de esas diferencias de frecuencias entre alelos que obedezcan a presiones selectivas individualizables. Y, si no perdemos de vista esa referencia a la selección natural, también podemos entender la diferencia que existe entre el concepto de ecotipo y un concepto de raza como el propuesto por Newton Freire-Maia.

Según este genetista de poblaciones, cuyos puntos de vista eran muy próximos de los de Dobzhansky, las razas podían ser definidas como "poblaciones, más o menos aisladas, que difieren de otras poblaciones de la misma especie por la frecuencia de características hereditarias" (Freire-Maia, 1988, p.316). Allí, el carácter arbitrario de la discriminación entre las poblaciones no parece tan claro; y, además, se subraya el aislamiento entre las poblaciones a ser discriminadas. Recono- 
ciéndose, sin embargo, que ese aislamiento puede ser mayor o menor. Pero, en clara divergencia con el concepto de ecotipo, ahí no se hace ninguna especificación sobre las causas de esas diferencias en las frecuencias de las características hereditarias consideradas. Para Freire-Maia no es necesario que, en algún grado mínimamente significativo, esa diferencia responda a la selección natural. En cambio, para el concepto de ecotipo eso es esencial. Si se acepta que las razas son ecotipos, sus diferencias tienen que obedecer a la selección natural; y es ahí en donde la noción de ecotipo parece coincidir con la de raza geográfica.

La idea de ecotipo no supone, entonces, el grado de aislamiento evolutivo, de limitación del flujo genético inter-poblacional, que la idea de subespecie parece exigir ( $c f$. Pigliucci \& Kaplan, 2003, p.1165). Tampoco exige que las diferencias inter-poblacionales en lo que atañe a la composición del pool genético y estado medio de caracteres sean particularmente amplias ( $c f$. Pigliucci \& Kaplan, 2003, p.1165). Sólo exige que esas diferencias sean, en parte, explicables por selección natural; y eso no deja de aplicarse al caso de las poblaciones humanas (Templeton, 2018, p.461). Por eso, afirman Pigliucci y Kaplan (2003, p.1161), el concepto de ecotipo es aplicable a Homo sapiens; y si se considera que dicho concepto equivale al de raza ecológica, también puede afirmarse que es dable establecer distinciones raciales en nuestra especie ( $c f$. Pigliucci \& Kaplan, 2003, p.1165). Las mismas, sin embargo, no se corresponderían ni con las 'razas folk' (cf. Pigliucci \& Kaplan, 2003, p.1167), ni con las tres, cuatro o cinco categorías raciales propuestas por naturalistas como Linneo, Blumenbach y Cuvier. Tampoco con las razas de la Antropología Forense y con aquellas de los censos. Y sobre este punto quiero hacer una breve digresión, que creo pertinente.

Refiriéndose a esa falta de correspondencia entre la noción de ecotipo y los modos más habituales de usar la noción de raza, John Dupré (2006, p.152) llegó a preguntarse si puede ganarse algo promoviendo la posición de Pigliucci y Kaplan; y su respuesta (a mí entender demasiado optimista) fue que esa identificación entre raza y ecotipo introduce una precisión que permitiría una mejor discusión de algunos problemas en don- 
de la noción de raza podría estar implicada (cf. Dupré, 2006, p.153). Por razones que explicaré en la próxima sección, yo pienso que ahí no hay ningún rédito en términos de precisión; sino todo lo contrario. Pero, antes de mostrar por qué es que pienso así, quiero hacer algunas observaciones sobre lo cuál puede ser el tipo de rédito a obtenerse en ese rescate de la noción de raza que Pigliucci y Kaplan han propuesto.

Es que, de alguna forma, pese a que, desde un punto de vista teórico, estos autores apuntan en la dirección de un cambio radical en el significado del término 'raza'; en lo que atañe a la función ideológica que la noción puede tener, ellos no dejan de preservar algún margen para su posible uso racista; y aquí subrayo la definición de racismo que di en la presentación. Pigliucci y Kaplan (2003, p.1168) no dejaron de resaltar, en efecto, que entre las características que definen a un ecotipo puede haber disposiciones cognitivas y emocionales seleccionadas en virtud de exigencias ecológicas específicas. No sorprende, por eso, que, David Stamos (2008, p.216) haya reivindicado la posición de Pigliucci y Kaplan para así sugerir la posible rehabilitación de cierto 'racismo moderado' (cf. Stamos, 2008, p.226). En este sentido, también es dable decir que las tesis de estos biólogos son convergentes con las de Neven Sesarcic (2010, p.158) y Nicholas Wade (2015, p.263).

\section{Tipos y poblaciones}

No pretendo negar, entretanto, que la noción de ecotipo parece más fácilmente aplicable a Homo sapiens que la noción de subespecie. Conforme lo que Templeton ha sabido mostrar, es difícil discriminar subespecies, presentes o pasadas, de nuestra especie; y hay razones biológicas para que ello sea así. Pero, con la noción de ecotipo no ocurre lo mismo. Evidentemente, una parte significativa de las diferencias genotípicas que se dan entre las diferentes poblaciones de nuestra especie, obedece a presiones selectivas; y eso nos permite hablar de ecotipos: con relativa independencia del aislamiento de esas poblaciones; $\mathrm{y}$ con total independencia de la filiación de sus integrantes. Lo que aun así no queda claro, es que la noción de ecotipo pueda 
considerarse como una aclaración de la noción de raza conforme ella suele ser usada cuando se habla de seres humanos; y la razón de eso ya la consideramos cuando discutimos la posibilidad de pensar a las razas humanas como subespecies. En este último caso, entretanto, la cuestión no era crucial porque vimos que no es dable distinguir subespecies de Homo sapiens; aunque si sea dable distinguir ecotipos. Pero, tanto en el caso de la noción de subespecie como en la noción de ecotipo, chocamos con una misma dificultad a la hora de querer establecer alguna equivalencia, sinonimia u homologación, entre esas nociones y la noción de raza conforme esta última suele ser usada en el caso de nuestra especie: se trata, concretamente, de la dimensión poblacional de ambas nociones.

Las subespecies son linajes de poblaciones; y los ecotipos son poblaciones. Por lo tanto, lo que define la membresía de un individuo o grupo a una subespecie o ecotipo es el hecho de estar integrado en una comunidad reproductiva; más allá de la filiación y de las características de esos individuos o grupos. Así, los descendientes de ucranianos que habitan en el nordeste de Argentina, pertenecen a la misma población de los descendientes de guaraníes que allí habitan. Esto es así aunque, en lo atinente a algunos caracteres, los descendientes de ucranianos no exhiban los valores medios que son propios de la población total; y que, en parte, pueden resultar de presiones selectivas resultantes de las condiciones ecológicas en las que esas poblaciones han evolucionado. Es decir: pese a sus peculiaridades, los descendientes de ucranianos deberán ser considerados como parte del mismo ecotipo que los descendientes de guaraníes; y eso no tiene nada de problemático. Pero, si aceptamos lo propuesto por Pigliucci y Kaplan, también tendremos que decir que esos descendientes ucranianos son parte de la misma raza que los descendientes de guaraníes de su misma población; y, por lo mismos motivos, también tendremos que decir que esos descendientes de ucranianos no son parte de la misma raza de la mayor parte de los actuales habitantes de Ucrania.

Es verdad: si por raza entendemos ecotipo, eso es así; y es inobjetable: se trataría de una cuestión resuelta 'por definición'. Pero lo que no está claro es si hay alguna razón para 
establecer esa equivalencia. Una elucidación conceptual tiene que compadecerse, mínimamente, de los usos de la noción a ser elucidada; y eso no parece ocurrir en este caso. No, por lo menos, en el caso de la noción de raza conforme ella ha sido usada en el caso de los seres humanos. Pero la verdadera razón de que eso sea así no reside ni en la casi inextricable maraña genealógica de las poblaciones humanas, ni en su consecuente polimorfismo genético y fenotípico. Lo que hace obstáculo para establecer esas pretendidas equivalencias conceptuales reside en las dificultades que plantea las diferencias entre una perspectiva tipológica y una perspectiva poblacional. La noción de raza humana es de cuño tipológico, y no parece poder encontrar una traducción satisfactoria en una perspectiva poblacional.

La noción de especie biológica nació, es verdad, en un contexto tipológico; pero pudo ser incorporada en una perspectiva poblacional. Hoy entendemos a las especies como linajes de poblaciones; y a partir de allí los taxones superiores pueden ser definidos como linajes de especies. A su vez, esa forma de pensar puede aplicarse al nivel subespecífico; y eso es lo que se hace cuando también se define a las subespecies como linajes de poblaciones. Pero, si se quiere establecer una equivalencia entre subespecie y raza, en general, y partir de ahí se quiere definir a las razas humanas como subespecies de Homo sapiens, las cosas ya no parecen funcionar tan bien. Y esto con independencia de que sea o no sea posible distinguir subespecies dentro de Homo sapiens. La membresía de un individuo a una subespecie se define por la membresía a una población de esa subespecie; y no por la posesión de ciertas características. Estas características, además de servirnos para inferir una filiación, también pueden servirnos, en muchos casos, como caracteres para diagnosticar de forma más o menos clara cuál es esa subespecie; pero lo que define esa membresía es el hecho de que el individuo en cuestión esté integrado en una población que pueda considerarse como sub-linaje de la sub-especie en cuestión. Y ese modo de razonar se extiende a los ecotipos.

En el caso de las especies de reproducción sexuada, que es el que nos interesa, el hecho de que un individuo se considere, o no, como parte de un ecotipo no depende de sus carac- 
terísticas, ni de su filiación, sino del hecho de estar integrado en la comunidad reproductiva, o población, a la que estamos considerando como ecotipo. Sin poder descartarse que ese individuo haya migrado desde otra población, o que esté integrado en más de una comunidad reproductiva; y, así, en más de un ecotipo. Y creo que aquí importa resaltar una diferencia entre la adscripción taxonómica de individuos y la adscripción taxonómica de linajes inferiores en linajes superiores. En este último caso, la filiación desempeña un papel, definitivo y crucial, que no tiene análogo en el caso de los individuos. Que una población de leones sea considerada como un linaje de Panthera leo leo, y no de Panthera leo persisa, dependerá de que esa población pueda ser considerada como un sublinaje dentro de un linaje mayor que estaría compuesto por todos los linajes de Panthera leo leo. En cambio, que un león individual sea considerado como parte de Panthera leo leo dependerá, básicamente, no de su propia filiación sino más bien de la filiación de la población en la que él está integrado.

Podrá haber, sin duda, algunos casos 'problemáticos'. En subespecies no tan aisladas como Panthera leo leo y Panthera leo persica, pueden darse individuos que, a lo largo de su vida, quizá en diferentes temporadas de apareamiento, se hayan integrado en distintas comunidades reproductivas, dejando ahí su descendencia. Sin que sea posible, incluso, apuntar una de esas comunidades como siendo su 'preferencial'. Pero, si en ese caso seguramente intentaríamos resolver el intríngulis taxonómico apelando a la filiación de ese individuo, o quizá a sus características heredadas; no por eso aceptaríamos que sus descendientes, si plena y exclusivamente integrados en una única comunidad reproductiva, fuesen considerados como integrantes de otra subespecie distinta de aquella a la cual adscribimos dicha población. Y eso con total independencia de las características heredadas de esos descendientes. Valiendo lo mismo, nuevamente, para el caso de la adscripción de un individuo a un ecotipo.

Como sea, lo que no puede dejar de reconocerse, es que el modo en que funcionan las atribuciones taxonómicas en la Biología contemporánea no parece dejar lugar para agrupa- 
mientos que podamos reconocer como razas humanas. Es decir: siguiendo los modos y criterios vigentes de la clasificación biológica, es difícil encontrar una categoría que pueda considerarse como correlato reconocible y significativo de las razas humanas ( $c f$. Biondi \& Richards, 2002). Aunque otras categorías originalmente pensadas en términos tipológicos hayan podido encontrar en correlato reconocible en la lógica poblacional de la Sistemática vigente, eso no parece ocurrir con las razas humanas. Las mismas parecen inasibles desde esa perspectiva que está en la base de la clasificación contemporánea. Es como si el núcleo tipológico, originario, de la noción de raza humana fuese recalcitrante a cualquier traducción que no lo preserve. Por eso, lo único que cabe concluir es que las razas humanas no son entidades cuya existencia pueda ser reconocida en términos de la Sistemática hoy vigente en Biología. El problema, sim embargo, excede a las claves bajo las cuales se piensa a las categorías taxonómicas, e involucra a todo el enfoque poblacional. Es ese enfoque el que, de por sí, es incompatible con ese carozo irreductiblemente tipológico de la idea de raza humana; y es por eso que la noción de ecotipo, aunque no se quiera erigirla en categoría taxonómica, tampoco puede operar de la manera en que Pigliucci y Kaplan lo pretenden.

\section{¿Asunto terminado?}

Como consecuencia de sus análisis, Alan Templeton (2018, p.463) llega a afirmar que "la historia evolutiva humana ha estado dominada por el flujo genético y por la mescla que unifica a la humanidad en un sólo linaje evolutivo". Creo, sin embargo, que, si se entiende que las poblaciones, cuando consideradas en perspectiva evolutiva, son, ellas mismas, linajes, o demes ${ }^{6}$, lo mejor sería decir que entre esas poblaciones y la propia especie no se pueden discernir otros linajes filoge-

$6 \quad$ Una población puede ser pensada de dos formas: puede ser considerada desde una perspectiva meramente ecológica, como agrupamiento de individuos de una misma especie que está integrado en un ecosistema particular; o puede considerarse evolutivamente como linaje, como deme. Esta distinción fue muy claramente establecida por Niles Eldredge (1985, p.88; 1996, p.194; 2016, p.3). Yo la discutí en un trabajo anterior (Caponi, 2016). 
néticamente reconocibles. Eso nos lleva a concluir que, en el caso de nuestra especie, la categoría taxonómica 'raza' no tiene correlatos reales. Es decir: fuera de las propias poblaciones, no hay linajes discernibles a los que se pueda considerar como filogenéticamente reales. Por eso, o se incurre en la rocambolesca idea de considerar a cada población humana como si fuese una raza, o se acepta que, por debajo de Homo sapiens, no hay taxones a los que quepa considerar como filogenéticamente reales. Desde ese punto de vista podemos estar seguros que las razas humanas son ficciones taxonómicas. Filogenéticamente hablando, y conforme Robert Sussman (2014) lo ha dicho, las razas humanas son un mito.

Lo cierto, sin embargo, es que, pese a su centralidad, la clasificación filogenética no es el único modo posible de clasificar a los seres vivos. Hay otros modos posibles de hacerlo. Los grupos reales a los que alude la Sistemática Filogenética son linajes: son entidades individuales cuya sistematización se establece según sus relaciones de filiación ${ }^{7}$. Pero se puede pensar en clasificaciones que, no aludiendo a linajes, aludan a clases, no a grupos o linajes. Clases que sean teóricamente significativas, o por lo menos útiles para organizar y transmitir la información. Las categorías homeotermo y poiquilotermo, que parten en dos al universo de los animales, son un buen ejemplo de lo primero: son clases teóricamente significativas. Que nos digan que un animal está incluido en una de ellas, nos indica algo relevante sobre su fisiología y nos permite hacer predicciones sobre lo que ocurriría con ese animal bajo determinadas condiciones. Pero los biólogos usan muchas otras taxonomías, más o menos informales, que responden a intereses teóricos diferentes, y que proponen otras clases dentro de las cuales adscribir a los diferentes seres vivos. Piénsese, por ejemplo, en categorías como 'predador' o 'polinizador'; o en categorías

$7 \quad$ Estoy asumiendo el 'individualismo taxonómico' explícitamente integrado por Willi Hennig (1968) en los fundamentos de su Sistemática Filogenética. Según dicha posición, hoy hegemónica en la Sistemática, los taxones biológicos son entidades individuales, y no clases naturales o tipos (cf. Ereshefsky: 2007, p.406; 2008, p.102). En los últimos años han surgido algunos cuestionamientos a la tesis que discutí en dos trabajos recientes ( $c f$. Caponi: 2017; 2018b). 
como 'organismo productor', 'organismo consumidor', y 'organismo descomponedor'.

Ellas son teóricamente significativas según el punto de vista biológico desde el cual son trazadas: su predicación tiene valor explicativo y predictivo. Si sabemos que un organismo es un 'predador' podremos explicar algo de su morfología, de su fisiología y de su comportamiento; y si sabemos que es un descomponedor podremos saber algo sobre su función en un ecosistema. Pero, también hay otras clasificaciones que no parecen tener ese valor epistémico. Piénsese, por ejemplo, en categorías como aquellas que permiten clasificar a las hojas por su forma. Parecería que ahí lo único que hay es un recurso para unificar el lenguaje con el cual describimos a las plantas y sus hojas. Decir que una planta tiene hojas lanceoladas, puede servir para identificarla; pero, prima facie, no parece indicar mucho sobre su fisiología y su ecología. Las categorías de la morfología foliar son útiles para comunicar y almacenar la información; pero, a primera vista, no parecen ser epistémicamente productivas o amplificativas.

En este sentido, y recordando a Nelson Goodman (1965, p.57-8), se puede incluso decir que las clases como predador $\mathrm{u}$ homeotermo permiten hacer proyecciones, o inferencias, desde propiedades conocidas, ya observadas o constatadas, hacia otras propiedades, o disposiciones, aun no constatadas o no manifestadas. Dadas las informaciones que nos permitan decir que estamos ante un organismo predador o polinizador, podemos inferir otras cosas sobre esos organismos que aún no hemos observado. Mientras tanto, la rúbrica 'Libros escritos por autores cuyos apellidos comienzan con K', o las categorías de morfología foliar como cordada, elíptica o lanceolada, no parecen propiciar esas proyecciones de lo constatado a lo aún no observado. Estas últimas clases, de acuerdo con John Stuart Mill, serían clases superficiales (Hacking, 2005, p.103). Las mismas, dice Mill (1974[1843], p.122), "tienen poco o nada en común que las caracterice, excepto aquello que es indicado por su nombre: las cosas blancas, por ejemplo, no se distinguen por ninguna otra propiedad común excepto la blancura"; y algo semejante ocurriría con 'Libros escritos por autores cuyos apellidos comienzan con K', o con 'hojas lanceoladas'. 
En lo que atañe a esa diferencia entre tipos de clases, se ha impuesto la polaridad entre clases naturales y artificiales. Así, mientras las clases como poiquilotermo y organismo consumidor serían naturales, las clases como 'Libros escritos por autores cuyos apellidos comienzan con K' son artificiales. Como bien lo explica Marzia Soavi (2009, p.185), las clases naturales son aquellas "cuyos ejemplos son objetos que comparten una o más propiedades que son fundamentales desde un cierto punto de vista teórico. Verbigracia, muestras de la misma clase química comparten la misma composición molecular o tienen el mismo número atómico". Por eso, "las clases naturales son caracterizadas como clases que sustentan poderosamente inducciones, es decir, permiten descubrir propiedades que son proyectables sobre sus ejemplos"; y es también por eso que ellas son habitualmente "contrapuestas a las clases cuyos ejemplos no comparten ninguna propiedad teóricamente relevante". Estas últimas "son a veces llamadas clases artificiales o, alternativamente, clases nominales" (Soavi, 2009, p.185). Pero, volviendo otra vez a Nelson Goodman (1965, p.121), se podría observar que el carácter genuino o artificial de una clase es cosa de grados.

Puede haber clases más naturales; o, usando la expresión de Goodman, más genuinas que otras. Y puede haber clases más o menos artificiales que otras. Es dable pensar, por lo tanto, en un gradiente que iría de clases, o rúbricas, meramente artificiales o nominales, a clases, o tipos, que podríamos caracterizar como 'naturales' o 'genuinos'. En el extremo de máxima artificialidad y mínima naturalidad, estaría una rúbrica como 'Libros escritos por autores cuyos apellidos comienzan con K'. Y es posible que las clases de la morfología foliar deban situarse un poco más lejos de ese extremo: esa morfología quizá guarde alguna correlación con la fisiología y la ecología de la planta en la que se da. Mientras tanto, homeotermo estaría alto en la escala de naturalidad, o de proyectabilidad; y lo mismo valdría para categorías como organismo productor u organismo consumidor. Así, usando el lenguaje de Mill, cabría también hablar de una escala de superficialidad decreciente, y profundidad creciente, en la que se podrían ordenar todas las clases. Las más proyectables serían las más naturales y profundas. Lo 
cierto, sin embargo, es que esa gradación también debería ser matizada. La naturalidad o profundidad de una clase siempre es relativa a un referencial epistémico o disciplinar.

Ella depende, como Marzia Soavi lo observó, de un punto de vista teórico. Para la Geología, los conceptos de isla volcánica e isla coralina son clases naturales altamente 'proyectables': ellas nos indican algo sobre la composición y la historia de las islas a las que una u otra categoría puedan ser aplicadas, y también nos permiten saber algo sobre los procesos geológicos que esas islas puedan sufrir en el futuro. Sin embargo, desde el punto de vista de la Ciencia Política, esas categorías no parecen demasiado relevantes. Como sí puede ser relevante, desde esa última perspectiva, la categoría 'Islas controladas por el Reino Unido'. Desde un punto de vista geológico, ella es nulamente informativa; pero sí es relevante desde un punto de vista político, jurídico y eventualmente cultural o económico. Y teniendo en cuenta eso hasta podemos ensayar una reivindicación de ' $\mathrm{Li}$ bros escritos por autores cuyos apellidos comienzan con K'. La misma nada nos dice sobre el contenido de esos libros; y, por eso, ella es irrelevante para la Teoría Literaria y para la Historia de la Cultura en general. Pero, aunque muy débilmente, ella puede informarnos algo sobre el origen de los autores de esos libros: si se trata de una biblioteca que incluye libros de escritores de todo el mundo, podremos considerar como probable que, dentro de esa rubrica, no encontremos muchos de origen español, portugués o italiano.

Así, y volviendo sobre el tema que nos ocupa, se podría pensar en la posibilidad de que las categorías raciales que se aplican a los humanos funcionen, en realidad, como clases más o menos naturales, o más o menos artificiales o superficiales. Siendo pertinente discutir, entonces, cuál sería la relevancia teórica, o quizá meramente práctica, que dichas categorías podrían tener. Al inicio ya propuse un nombre y una caracterización de esas categorías: las denominé 'tipos fisonómicos'; y las describí como agrupamientos de rasgos o particularidades distinguibles a simple vista, que pueden ser usados para clasificar a los seres humanos. De lo que se trata ahora es de preguntarnos si esas clasificaciones pueden tener alguna relevancia o utilidad; o si sería 
mejor abandonarlas dado el consabido uso que de ellas siempre ha hecho y continúa haciendo el racismo. Conocidas todas las iniquidades a las que el racismo ha dado lugar, asumida además su falta de fundamento, es dable pensar que, en el caso de nuestra especie, las categorizaciones raciales deberían ser definitivamente abandonadas, considerándolas como una amenaza a ser sistemáticamente combatida. Sobre todo, cuando ya hemos reconocido que, en Homo sapiens no existen linajes subespecíficos que sirvan de base a las taxonomías raciales. Con todo, puede constatarse que, en diferentes contextos, las categorías raciales, entendidas como meros tipos fisonómicos ( $c f$. Cartmill, 1998, p.659), desempeñan algunas funciones; y eso puede llevarnos a pensar que dichos tipos pueden tener algún valor epistémico y que no son tan fácilmente dispensables.

\section{Raza, salud y sociedad}

All red-headed men who are sound in body and mind, and above the age of twenty-one years, are eligible. ${ }^{8}$

La Antropología Forense es uno de esos contextos en donde los tipos raciales parecen tener un valor epistémico reconocible y efectivo (Hochman, 2013, p.279); aunque ciertamente muy limitado. A partir de los restos óseos de una persona, es posible una determinación relativamente confiable y precisa de cuál sería el tipo fisonómico a la que lo mismo pudo responder cuando viva. Esto parece cumplirse con más regularidad en caso de los tipos fisonómicos negro y caucásico, conforme suelen ser entendido en los Estados Unidos y en Europa (Sauer, 1992, p.110; Adams, 2007, p.43); y tampoco deja de funcionar, aunque con menor confiabilidad, en el caso de asiáticos, y amerindios (Sauer, 1992, p.110; Adams, 2007, p.44). Por lo menos, insisto, conforme esos tipos fisonómicos son entendidos y definidos en ciertos países (Sauer, 1992, p.109; Adams, 2007, p.43). Pero, no obstante el entusiasmo que dicha posibilidad despierta en algunos autores racistas como Neven Se-

\footnotetext{
8 De un aviso publicado en The Morning Chronicle, el 27 de abril de 1890, según consta en The red-headed league (Conan Doyle, 1989[1891], p.134).
} 
sarcic (2010, p.156) y Nicholas Wade (2015, p.79), lo cierto es que, desde un punto de vista estrictamente biológico, esa correlación entre esqueleto y fisonomía no es demasiado significativa; y ella nada nos dice sobre la realidad filogenética de las razas humanas (Sauer, 1992, p.109; Cartmill, 1998, p.659; Ousley et al, 2009, p.74).

Dicha correlación sólo nos indica dos cosas: que la forma del rostro está de hecho muy determinada por la morfología del cráneo (Adams, 2007, p.43); y también que existe una cierta correspondencia, ya un poco menos segura, entre ciertos aspectos de la morfología ósea y otros rasgos como el color de la piel y del cabello (Sauer, 1992, p.110). Esto no parece demasiado revelador; pero si nos interesa diseñar procedimientos para identificar a las personas y trasmitir información sobre ellas, esa proyección desde el hueso a la fisonomía puede ser provechosa (Sauer, 1992, p.108). En base a la misma, la tipificación racial de una persona (junto con datos sobre su edad, estatura, contextura y sexo) podrá ayudarnos a saber si ciertos restos mortales encontrados son o no los suyos (Adams, 2007, p.31). Y, de hecho, parece que así ocurre con no poca frecuencia (Sauer, 1992, p.110). Los tipos fisonómicos, para decirlo de otro modo, nos permiten hacer proyecciones desde los individuos que los ejemplifican hacia sus restos óseos; y desde esos restos a dichos individuos.

No es ese, entretanto, el único caso en que las tipificaciones raciales, aun entendidas como meros tipos fisonómicos, pueden tener alguna relevancia epistémica (Putzke et al, 2002). En el caso de la Medicina, esos tipos pueden usarse como indicadores de riesgo de alguna confiabilidad (Rosenberg et al, 2002, p.2384). Que un individuo responda al tipo fisonómico negro, puede indicarnos la posibilidad de que él sea portador del alelo de la hemoglobina S. Eso haría que él fuese resistente a la malaria; pero también aumentaría la probabilidad de que la anemia falciforme se dé entre sus descendientes (Hacking, 2005, p.107). Es que, dicho tipo fisonómico puede indicar una ascendencia que remita a poblaciones de ciertas regiones del África subsahariana en donde, debido a una alta incidencia de malaria, operan, u operaron, presiones selectivas favorables al alelo de la 
hemoglobina S (Cabrera, 2018, p.505): el mismo alelo que, en el portador heterocigoto, resulta en resistencia al plasmodio causador de la malaria (Templeton, 2016, p.463); y que, en el caso de portador homocigoto, produce la mortal anemia falciforme (Templeton, 2016, p.463; Cabrera, 2018, p.505).

Pero esto, siempre vale aclararlo, no es algo que esté causalmente vinculado con los factores genéticos que definen el tipo fisonómico negro. No hay una vinculación pleitrópica entre ese alelo y los alelos vinculados con el color de piel o la forma de los arcos superciliares. La anemia falciforme, hablando mal y pronto, no es una enfermedad de negros (Templeton, 2016, p.463). Ella es, simplemente, una enfermedad frecuente en poblaciones de ciertas regiones y relativamente probable entre aquellos cuya ascendencia remita tales poblaciones. Es por eso que el tipo fisonómico negro se trasforma en un proxy relativamente significativo del alelo de la hemoglobina S ( $c f$. Hacking, 2005, p.107). Dicho tipo es preponderante en la mayor parte de las regiones en donde hay alta incidencia de malaria; $\mathrm{y}$, por eso, la sospecha de que un individuo tenga parte de su ascendencia en esas poblaciones, también resulta en la advertencia de que dicho individuo puede ser portador de un alelo que, en sus descendientes, puede producir una enfermedad mortal. Así, los trazos fisonómicos que indicarían la posibilidad de esa ascendencia se trasforman en indicadores de riesgo; sin por eso ser causa, o síntoma, de ninguna enfermedad.

Por otra parte, en lo que atañe a esto, es menester no olvidar que el tipo fisonómico no es un predictor muy confiable de ascendencia ( $c f$. Parra et al, 2003, p.181; Pena \& Bortolini, 2004, p.46); y también hay que tener en cuenta que la presión favorable a dicho alelo también opera, $\mathrm{y}$ ha operado, en poblaciones en las cuales pueden, o podían, coexistir individuos asignables a diferentes tipos fisonómicos. Dándose incluso el caso de poblaciones de la región mediterránea en donde predomina el tipo caucásico y en las cuales se da la misma asociación entre incidencia de la malaria y frecuencia del alelo de la hemoglobina $\mathrm{S}$ que se verifica en el África subsahariana (cf. Hacking, 2005, p.107; Templeton, 2016, p.463). Con todo, como la asociación entre el tipo caucásico y la ascendencia en poblaciones 
de esas regiones mediterráneas no es tan fuerte, el simple hecho de que un individuo presente rasgos caucásicos, no puede tomarse como indicador de riesgo en lo atinente al alelo en cuestión. Aunque sí podría valer como indicador cualquier dato, no necesariamente biológico, que nos hiciese sospechar esa ascendencia mediterránea. Un apellido podría ser un ejemplo de eso. Tal como ocurre con la enfermedad de Tay-Sachs y el hecho se ser portador de un apellido ashkenazi ( $c f$. Gravel et al, 1991, p.421; Triggs-Raine et al, 1990, p.11; Rozemberg \& Pereira, 2001, p.146; Hacking, 2005, p.107).

Hay que tener mucho cuidado, de todos modos, con estas posibles, y muchas veces sólo conjeturadas, vinculaciones entre ascendencia y riesgos médicos. Las mismas, conforme nos alerta Carlos López Beltrán (2016, p.190), pueden inducirnos a no ver que ciertos problemas de salud pueden estar asociados a las condiciones de vida a las que están sometidos determinados grupos, o a los hábitos que esos grupos han debido adquirir en virtud de dichas condiciones. El recurso genético a la ascendencia puede llevarnos, en efecto, a desviar nuestra mirada de una posible conexión entre el problema médico y una cuestión políticamente intervenible, haciendo que pongamos dicha mirada sobre la herencia: algo que no se puede cambiar y a lo que, de algún modo, tenemos que resignarnos.

Existen, sin embargo, ciertos riesgos médicos cuyo vínculo causal con el tipo fisonómico es más claro que esos que acabo de mencionar. Uno de ellos es la relación que existe entre la piel clara, asociada al tipo caucásico, y el desarrollo de ciertas formas de cáncer de piel (Parra, 2011, p.74). En este caso, hay una conexión causal inmediata entre ambas cosas: la piel es más clara en virtud de una menor producción de melanina; y esto, redundando en una menor protección a los rayos ultravioletas provenientes de la radiación solar, facilita el desarrollo de ciertos tipos de tumores (Parra, 2011, p.74). Pero, en razón de la mayor producción de melanina, las pieles oscuras, como es el caso de las asociadas al tipo negro, también pueden redundar en algún riesgo para la salud. El filtro de los rayos ultravioletas que produce la melanina puede dificultar la producción de vitamina D. Por eso, para producir la vitamina 
D que necesita, una persona de piel oscura requiere hasta diez veces más exposición al sol que una persona de piel clara (Parra, 2011, p.74). Y esa demanda puede ser difícil de atender en latitudes altas. Así, mientras en latitudes más bajas el tipo caucásico está asociado al riesgo de desarrollar cáncer de piel; en latitudes altas, el tipo negro puede estar asociado al déficit de vitamina D. Y ambas cosas deberían ser consideradas en políticas de prevención (Parra, 2011, p.74).

Pero, la eventual relevancia que los tipos raciales tendrían para la Medicina, puede ir más allá de los riesgos de desarrollar ciertas patologías. Es dable pensar que, en algunos casos, la propia intervención terapéutica puede estar condicionada por variables asociadas con los tipos raciales. Un caso puede ser el de la eficacia de algunos medicamentos. Dicha eficacia puede estar genéticamente condicionada; y es posible que, en algunos casos, ese condicionamiento esté vinculado con la ascendencia que el paciente denuncia en virtud de su tipo fisonómico (Kitcher, 2007, p.315). Por eso, en algunas circunstancias muy específicas, tener en cuenta esa fisonomía puede permitir una mejor elección del fármaco a ser prescripto (Hacking, 2005, p.107). Sin embargo, el ejemplo más dramático de ese condicionamiento que la ascendencia, denunciada por el tipo fisonómico, puede traer para la estrategia terapéutica, parece residir en las dificultades que para encontrar donantes de médula que suele afectar a los pacientes negros que padecen leucemia ( $c f$. Kitcher, 2007, p.312). El sistema inmune de los descendientes de algunas poblaciones africanas restringe el universo de los donantes posibles de una forma que no tiene equivalente en los que no comparten esa ascendencia. Esto puede hacer recomendable un esfuerzo colectivo por la ampliación del número de donadores que, por responder al tipo fisonómico negro, tengan más probabilidades de ser compatibles con posibles receptores de la misma condición (cf. Hacking, 2005, p.108).

Se puede decir, en resumen, que, si considerados en términos estrictamente biológicos, los tipos raciales, entendidos meros tipos fisonómicos, tienen algún valor cognitivo: quizá no muy significativo desde un punto de vista puramente teórico; pero sí, quizá, desde un punto de vista práctico. En 
la Antropología Forense, y siempre dentro de ciertos límites, ellos permiten ir desde la fisonomía a la estructura y desde el resto óseo hasta esa misma fisonomía. En Medicina, mientras tanto, esos tipos fisonómicos no sólo pueden funcionar como indicadores de riesgo en lo que atañe a ciertas patologías; sino que también pueden operar como referencia a ser considerada en la elección y aplicación de algunas estrategias terapéuticas. Pero, aunque esos tipos fisonómicos remitan a rasgos y configuraciones corporales, y estén asociados con factores genéticos, su mayor relevancia cognitiva no tiene que ver con los procesos biológicos, sino que se inscribe en el plano de los procesos sociales. Los tipos fisonómicos pertenecen al dominio de esos fenómenos biológicos que inciden, muy acentuadamente, en el dominio de los procesos sociales; y es ahí que reside su carácter más problemático. El hecho de que un individuo responda a un tipo fisonómico u otro, puede incidir en su forma insertarse y de funcionar dentro de ciertos contextos y espacios sociales.

En Argentina, por ejemplo, el trato que la policía puede depararle a un individuo suele variar en función de si ese individuo responde al tipo fisonómico caucásico o a cualquier cosa próxima del tipo fisonómico amerindio. Valiendo lo mismo con relación a las oportunidades de empleo y también con relación al acceso a ciertos lugares de esparcimiento. Sin contar, con discriminaciones quizá menos frecuentes, pero no por eso menos decisivas en la historia individual de una persona, como pueden ser las que ejerce un educador, un profesional de la salud, un juez, o el encargado de otorgar un crédito bancario. Algo muy semejante a lo que ocurre en Brasil, sobre todo, con el tipo fisonómico negro. Eso preserva y ahonda desigualdades seculares, transformando a esos tipos en verdaderos estigmas que refuerzan la marginación y la vulnerabilidad de quienes responden a ellos.

Así, en situaciones como esas que se dan en Argentina y en Brasil, pero también en muchos otros lugares, los tipos fisonómicos socialmente segregados pueden ser usados como indicadores, y hasta como predictores, de riesgos y de vulnerabilidades de todo tipo. Ellos nos indicarán, sobre todo, que los individuos a los que tales tipos de aplican tendrán, en media, 
más probabilidades de estar sujetos a tratos inicuos, y a discriminaciones marginalizantes, que aquellos individuos que no responden a tales tipos. Siendo que, en muchos casos, y quizá en la mayoría, ese trato inicuo y discriminatorio no obedecerá a otra causa que al tipo fisonómico. Es decir: en no pocos casos, el tipo fisonómico servirá para explicar, causalmente, lo que le ocurre a un individuo.

Esto puede parecer muy obvio; pero no está demás señalarlo porque nos sirve para disolver algunos sofismas que circulan por ahí. En algunos casos parecería que, del hecho de que las razas humanas no existan como entidades filogenéticamente discernibles, y así reconocibles en la sistemática biológica vigente, se debería inferir que los problemas raciales no existen. Pero, del mismo modo en que la inexistencia de la raza pelirroja, en cuanto que entidad filogenéticamente real, no implica que los pelirrojos no existan; la inexistencia de la raza negra, en cuanto que realidad filogenética, no implica que los negros no existan. Y, del mismo modo en que los pelirrojos tienen características que, en ciertos contextos, los hacen propensos a ciertos cánceres de piel, el hecho de responder a los tipos fisonómicos negro o amerindio hace que, en ciertos contextos sociales, se esté particularmente expuesto a ser víctima de iniquidades y discriminaciones de todo tipo. Por eso, así como la condición de pelirrojo puede hacer recomendable que un individuo tome algunos cuidados especiales con su piel y con la exposición a la radiación solar, el hecho de que un individuo responda al tipo negro puede llevarnos a aceptar que él sea beneficiario de algún tipo de discriminación positiva tendiente a compensar y a paliar, en la medida de lo posible, las consecuencias de las iniquidades y de las discriminaciones marginalizantes a las que ese individuo pudo estar, o puede llegar a estar, sujeto.

Por otra parte, dado que la condición de posibilidad de la discriminación negativa reside principalmente en la condición de pobreza y marginación de los grupos que responden a los tipos fisonómicos que son víctimas de esa inequidad, las acciones afirmativas, al promover una reversión parcial y progresiva de esa desigualdad, también tienden a erosionar la pro- 
pia condición de posibilidad de dicha discriminación. Cuantos más individuos que respondan a los tipos discriminados estén ocupando posiciones de algún prestigio y poder, menor tenderá a ser la discriminación en contra de esos tipos; y creo que esa es la razón más fuerte para la promoción de políticas afirmativas. Pero, para implementar estas políticas es necesario que se reconozcan los tipos fisonómicos que caracterizan a las víctimas de la discriminación negativa y que habrán de identificarse en los beneficiarios de las discriminaciones positivas. En este sentido, hay que admitirlo, Demetrio Magnoli (2009, p.366) tiene razón: una política como la de 'cupos raciales' para el ingreso a la universidad supone una rotulación de los individuos en virtud de tipos fisonómicos. Eso, entre tanto, no tiene nada que ver con la discusión sobre la existencia filogenética de las razas humanas; y mezclar los dos asuntos, denunciando además por racistas a las políticas afirmativas (cf. Magnoli, 2009, p.165), es sólo una vulgar chicana.

Esos tipos, por otra parte, no se establecen en virtud de los genes que puedan explicarlos, ni tampoco en virtud de la filiación que pueda explicar la configuración del genotipo de un individuo. Los tipos fisonómicos aluden, como ya dije, a características visibles. Que son las mismas que hacen que un individuo pueda ser objeto de discriminación negativa. Nadie es impedido de entrar en un ascensor por sus genes, ni por su ascendencia: lo que lo hace víctima de eso es su cara; y es por esa misma cara que esa persona podrá ser beneficiaria de una política afirmativa. Por eso, el hecho de que exista incongruencia entre fisonomía y datos genéticos sobre ascendencia ( $c f$. Maio \& Santos: 2005a; 2005b), en nada compromete a las políticas afirmativas. Éstas deben aludir a lo que es objeto de discriminación negativa, erigiéndolo en objeto de discriminación positiva; $y$, en lo que atañe a eso, la Genética no tiene nada para decir. Ella nos ha mostrado evidencias que nos llevan a negar la inexistencia filogenética de las razas humanas; pero nada nos ha dicho sobre el posible delineamiento de tipos fisonómicos que pueden ser relevantes en diferentes ámbitos, entre los cuales se destaca el estudio de ciertos fenómenos sociales y el diseño de determinadas políticas públicas (cf. Pigliucci \& Kaplan, 2003, p.1170). 


\section{Conclusión}

Con Darwin (1859, p.456) ${ }^{9}$, la taxonomía biológica comenzó a ser entendida, por lo general, y con mayor o menos rigor, como filogenia ${ }^{10}$. En ese marco, los diferentes taxones pasaron a ser considerados como linajes y no ya como clases, naturales o artificiales, que pudiesen delinearse en virtud de afinidades morfológicas, organizacionales, o de alguna otra naturaleza. Asumiendo esa perspectiva filogenética, expresiones como Panthera leo y Vertebrata ya no designarían clases a la cual perteneciesen todos los animales que compartiesen ciertas características particulares. En lugar de eso, ambos términos, al igual que todos los nombres de subespecies o de especies, y al igual que todos los nombres de taxones superiores, pasarían a ser pensados como designaciones de entidades concretas producidas por la evolución y sujetas, ellas mismas, a cambios evolutivos, e incluso a la extinción. Por eso, cuando se dice que las razas humanas no son linajes que puedan ser reconocidos como taxones, también se está diciendo que ellas no son entidades concretas resultantes de procesos evolutivos y sujetas a tales procesos. Desde ese punto de vista, las razas humanas no son nada: no existen. Pero, si se considera que las razas humanas son meros tipos fisonómicos, lo que sí se puede decir, es que existen individuos que conforman la extensión de tales tipos. Y eso, según lo acabamos de ver, puede permitirnos saber algo sobre dichos individuos, justificando también que se tomen, $\mathrm{o}$ acepten, ciertas providencias y actitudes a su respecto.

\footnotetext{
$9 \quad$ Sobre este punto la literatura secundaria es unánime. Como ejemplos, véase: Hennig (1968, p.27); Eldredge \& Cracraft (1980, p.156); Mayr (1998, p.155); Tassy (1998, p.45); Llorente (1998, p.87); Le Guyader (2003, p.30); y Richards (2009, p.182).

10 Con esto quiero aludir a la Sistemática Filogenética (cf. Hennig, 1968, p.13; Eldredge \& Cracraft, 1980, p.239); pero también a la clasificación darwiniana tradicional propugnada por Simpson (1945, p.4; 1961, p.53) y Mayr (1998, p.155).
} 


\section{Referencias}

ADAMS, B. Forensic Anthropology. New York: Infobase publishing, 2007.

ANDREASEN, R. The meaning of 'race': folk conceptions and the new Biology of race. Journal of Philosophy, v.102, 2005, p. 94-106.

ANDREASEN, R. A new perspective on the race debate. In: SOBER, E. (Ed.). Conceptual issues in Evolutionary Biology. Cambridge: MIT Press, 2006. p. 477-501.

BIONDI, G. \& RICKARDS, O. The scientific fallacy of the human biological concept of race. Mankind, v.42, 2002, p. 355-388.

CABRERA, M. Malaria y hemoglobina S: ¿resistencia o protección? Medisur, v.16, 2018, p. 504-510.

CAPONI, G. Las especies son linajes de poblaciones microevolutivamente interconectadas: una mejor delimitación del concepto evolucionario de especie. Principia, v.17, 2013, p. 3995-418.

CAPONI, G. Lineages and systems: a conceptual discontinuity in biological hierarchies. In: ELDREDGE, Niles; PIEVANI, Telmo; SERRELLI, Emanuele; TËMKIN, Ilya (eds.): Evolutionary theory: a hierarchical perspective. Chicago: Chicago University Press, 2016, p. 47-62.

CAPONI, G. Los taxones tampoco son racimos homeostáticos de propiedades. Disputatio, v.6, 2017, p. 323-356.

CAPONI, G. Lo natural, lo seglar y lo sobrenatural. Revista de Humanidades de Valparaíso, v.14, 2018a, p. 27-55.

CAPONI, G. Esencia e identidad en Filosofía de la Taxonomía. Culturas Científicas, v.1, 2018b, p. 1-15.

CARTMILL, M. The status of the race concept in Physical Anthropology. American Anthropologist, v.100, 1998, p. 651-660.

CONAN DOYLE, A. The red-headed league (from The adventures of Sherlock Holmes [1891]). In: CONAN DOYLE, A. Sherlock Homes: the complete facsimile edition. Hertfordshire: Wordsworth, 1989, p. 132-146.

COYNE, J. \& ORR, A. Speciation. Sunderland: Sinauer, 2004.

DARWIN, C. On the origin of species. London: Murray, 1859.

DE QUEIROZ, K. Branches in the lines of descent: Charles Darwin and the evolution of the species concept. Biological Journal of the Linnean Society, v.103, 2011, p. 19-35.

DOBZHANSKY, T. Genetics and the origin of species. New York: Columbia University Press, 1951.

DUPRÉ, J. El legado de Darwin. Buenos Aires: Katz, 2006. 
ELDREDGE, N. Unfinished synthesis. Oxford: Oxford University Press, 1985.

ELDREDGE, N. Reinventing Darwin. London: Phoenix, 1996.

ELDREDGE, N. The checkered career of hierarchical thinking in Evolutionary Biology. In: ELDREDGE, N.; PIEVANI, T.; SERRELLI, E.; TËMKIN, I. (Ed.): Evolutionary theory: a hierarchical perspective. Chicago: Chicago University Press, 2016, p. 1-16.

ELDREDGE, N. \& CRACRAFT, B. Phylogenetic patterns and the evolutionary process. New York: Columbia University Press, 1980.

ERESHEFSKY, M. Species, taxonomy, and Systematics. In: MAUTHEN, M. \& STEPHENS, C. (Ed.). Philosophy of Biology. Amsterdam: Elsevier, 2007, p. 403-428.

ERESHEFSKY, M. Systematics and Taxonomy. In: SARKAR, S. \& PLUTYNSKI, A. (Ed). Companion to the Philosophy of Biology. Oxford: Blackwell, 2008, p. 99-118.

FREIRE-MAIA, N. De Darwin à Teoria Sintética. Belo Horizonte: Itatiaia, 1988.

FUTUYMA, D. Evolution. London: Sinauer, 2005.

GOODMAN, N. Fact, fiction, and forecast. Indianapolis: Bob-Merril, 1965.

GOULD, S. ¿Qué es, si es que es algo, una cebra? In: GOULD, S. Dientes de gallina y dedos de caballo. Madrid: Blume, 1984, p. 377-388.

GOULD, S. La falsa medida del hombre. Buenos Aires: Orbis, 1988.

GOULD, S. La igualdad humana es un hecho contingente de la historia. In: GOULD, S. La sonrisa del flamenco. Barcelona: Crítica, 1995, p. 157-168.

GRAVEL, R.; TRIGGS-RAINE, B.; MAHURAN, D. Biochemistry and genetics of Tay-Sachs Disease. Le journal canadien des sciences neurologiques, v.18, 1991, p. 419S-423S.

HACKING, I. Why race stills maters. Daedalus, v.134, 2005, p. 102-116.

HENNIG, W. Elementos de Sistemática Filogenética. Buenos Aires: Eudeba, 1968.

HERRSTEIN, R. \& MURRAY, C. The bell curve. New York, Free Press, 1994.

HOCHMAN, A. Racial discrimination: how not to do it. Studies in History \& Philosophy of Biological and Biomedical Sciences, v.44, 2013, p. 278-286. 
INTERNATIONAL COMMISSION OF ZOOLOGICAL NOMENCLATURE. Code International de Nomenclature Zoologique. London: The International Commission of Zoological Nomenclature, 1999.

KATTMANN, U. Race, genes and culture. In: KOEGELER, M. \& PARNCUTT, R. (Ed.): Interculturality. New Castle: Cambridge Scholar Publishing, 2013, p. 130-184.

KITCHER, P. Does 'race' have a future? Philosophy \& public affairs, v.35, 2007, p. 293-317.

LE GUYADER, H. Classification et évolution. Paris: Le Pommier, 2003.

LEWONTIN, R.; ROSE, S.; KAMIN, L. No está en los genes: racismo, genética e ideología. Barcelona: Crítica, 2003.

LINCOLN, R.; BOXSHALL, G.; CLARCK, P. Diccionario de Ecología, Evolución y Taxonomía. México: Fondo de Cultura Económica, 2009.

LIPKO, P. \& DI PASQUO, F. De cómo la Biología asume la existencia de razas en el Siglo XX. Scientiae Studia, v.6, 2008, p. 219-233.

LLORENTE, J. La búsqueda del método natural. México: Fondo de Cultura Económica, 1998.

LÓPEZ BELTRÁN, C. Escenarios de la patologización racial: la anomalía amerindia en una nación enferma. Metatheoria, v.8, 2018, p. 181-193.

MacEACHERN, S. The concept of race in contemporary Anthropology. In: SCUPIN, R. (Ed.). Race and ethnicity. New York: Prentice-Hall, 2011, p. 34-57.

MAGNOLI, D. Uma gota de sangue. São Paulo: Contexto, 2009.

MAI, L.; OWL, M.; KERSTING, P. The Cambridge Dictionary of Human Biology and Evolution. Cambridge: Cambridge University Press, 2005.

MAIO, M. \& SANTOS, R. Política de cotas raciais, os 'olhos da sociedade' e os usos da Antropologia: o caso do vestibular da Universidade de Brasília. Horizontes Antropológicos, v.11, 2005a, p. 181-214.

MAIO, M. \& SANTOS, R. As cotas raciais nos horizontes da Antropologia. Horizontes Antropológicos, v.11, 2005b, p. 292-308.

MAYDEN, R. On biological species, species concepts and individuals in the nature world. Fish \& Fisheries, v.3, 2002, p. 171-196.

MAYR, E. Systematics and the origin of species. Cambridge: Harvard University Press, 1942.

MAYR, E. Animal species and evolution. Cambridge: Harvard University Press, 1963.

MAYR, E. Así es la Biología. Madrid: Debate, 1998. 
MAYR, E. Species concepts and their application [1963]. In: RUSE, M. (Ed.). Philosophy of Biology. Amherst: Prometheus, 2007: p. 203-213

MAYR, E. The Biological Species Concept. In: WHEELER, Q. \& MEIER, R. (Ed.). Species concepts and Phylogenetic Theory. New York: Columbia University Press. 2000, p. 17-29.

MILL, J. A System of Logic. Toronto: University of Toronto, 1974[1843].

OUSLEY, S.; JANTS, R.; FREID, D. Understanding race and human variation: why forensic anthropologist are good at identifying race. American Journal of Physical Anthropology, v.139, 2009, p. 68-76.

PARRA, E. Evolución de la pigmentación en la especie humana. Piel, V.26, 2011, p. 66-79.

PARRA, F.; AMADO, R.; LAMBERTUCCI, J.; ROCHA, J.; ANTUNES, C.; PENA, S. Color and genomic ancestry in Brazilians. Proceedings of the National Academy of Science, v.100, 2003, p. 177-182.

PENA, S. \& BORTOLINI, M. Pode a Genética definir quem deve se beneficiar das cotas universitárias e demais ações afirmativas? Estudos Avançados, v.18, 2004, p. 31-50.

PIGLIUCCI, M. What are we to make on the concept of race? Studies in History \& Philosophy of Biological and Biomedical Science, v.44, 2013, p. 272-277.

PIGLIUCCI, M. \& KAPLAN, J. On the concept of biological race and its applicability to humans. Philosophy of Science, v.70, 2003, p. 1161-1172.

PUTZKE, J.; HICKEN, B.; RICHARDS, S. Race: predictor versus proxy variable? Archives of Physical Medicine and Rehabilitation, v.83, 2002, p. 1603-1611.

RICHARDS, R. Classification in Darwin's origin. In: RUSE, M. \& RICHARDS, R. (Ed.). The Cambridge Companion to the Origin of Species. Cambridge: Cambridge University Press, 2009, p. 173-193.

RICHARDS, R. Solving the species problem. In: RUSE, M. (Ed.). Philosophy of Biology. Amherst: Prometheus, 2007, p. 215-227.

RICHARDS, R. The species problem. Cambridge: Cambridge University Press, 2010.

ROSENBERG, N.; PRITCHARD, J.; WEBER, J.; CANN, H.; KIDD, K.; ZHIVOTOVSKY, L.; FELDMAN, M. Genetic structure of human population. Science 298, 2002, p. 2381-2385.

ROZEMBERG, R. \& PEREIRA, L. The frequency of Tay-Sachs Disease in the Brazilian Jewish population justifies a carrier of screening program. São Paulo Medical Journal, v.119, 2001, p. 146-149. 
SANTOS, R.; CALDAS, A.; BORGES, G.; VALENTE, J.; PORTELA, M.; MARINHO, G. Mortalidade infantil segundo cor ou raça com base no censo demográfico de 2010 e nos sistemas nacionais de informação em saúde no Brasil. Cadernos de Saúde Pública, v.33, 2017, e00046516.

SAUER, N. Forensic Anthropology and the concept of race. Social Science \& Medicine, v.34, 1992, p. 107-111.

SESARDIC, N. Confusions about races. Biology \& Philosophy, v.25, 2010, p. 143-162.

SIMPSON, G. The principles of classification and a classification of mammals. New York: American Museum of Natural History, 1945.

SIMPSON, G. The species concept. Evolution, v.5, 1951, p. 285-298.

SIMPSON, G. Principles of Animal Taxonomy. New York: Columbia University Press, 1961.

SPENCER, Q. A radical solution to the race problem. Philosophy of Science, v.81, 2014, p. 1025-1038.

STAMOS, D. Evolución. Barcelona: Buridán, 2008.

SOABI, M. Realism and artifact kinds. In: KROHS, U. \& KROES, P. (Ed.). Functions in biological and artificial worlds. Cambridge: MIT Press, 2009, p. 185-202.

SUSSMAN, R. The myht of race. Cambridge: Harvard University Press, 2014.

TASSY, P. L'arbre à remonter le temps. Paris: Diderot, 1998.

TEMPLETON, A. Human races: a genetic and evolutionary perspective. American Anthropologist, v.100, 1998, p. 632-650.

TEMPLETON, A. Biological races in humans. Studies in History \& Philosophy of Biological and Biomedical Sciences, v.44, 2013, p. 262-271.

TEMPLETON, A. La evolución y el concepto de raza humana. In: LOSOS, J. \& LENSKI, R. (Ed.). Cómo la evolución configura nuestras vidas. Barcelona: Buridán, 2018, p. 447-466.

TORRETTI, R. La proliferación de los conceptos de especie en la Biología Evolucionista. Theoria, v.69, 2010, p. 325-377.

TRIGGS-RAINE, B.; FEIGENBAUM A.; NATOWICZ, M.; SKOMOROWSKI, M.; SCHUSTER, S.; CLARKE, J.; MAHURAN, D.; KOLODNY, E.; GRAVEL, R. 1 Screening for carriers of Tay-Sachs Disease among Ashkenazi Jews. The New England Journal of Medicine, v.323, 1990, p. 6-12.

TURESSON, G. The species and the variety as ecological units. Hereditas, v.3, 1922a, p. 100-113. 
TURESSON, G. The genotypical response of the plant species to the habitat. Hereditas, v.3, 1922b, p. 211-350.

WADE, N. Una herencia incomoda. Barcelona: Ariel, 2015.

WILEY, E. Phylogenetics. New York: Wiley, 1981.

WILEY, E. \& LIEBERMAN, B. Phylogenetics. Hoboken: Wiley \& Blackwell, 2011.

WOOD, A. What, if anything, is a rabbit? Evolution, v.11, 1957, p. 417-425. 